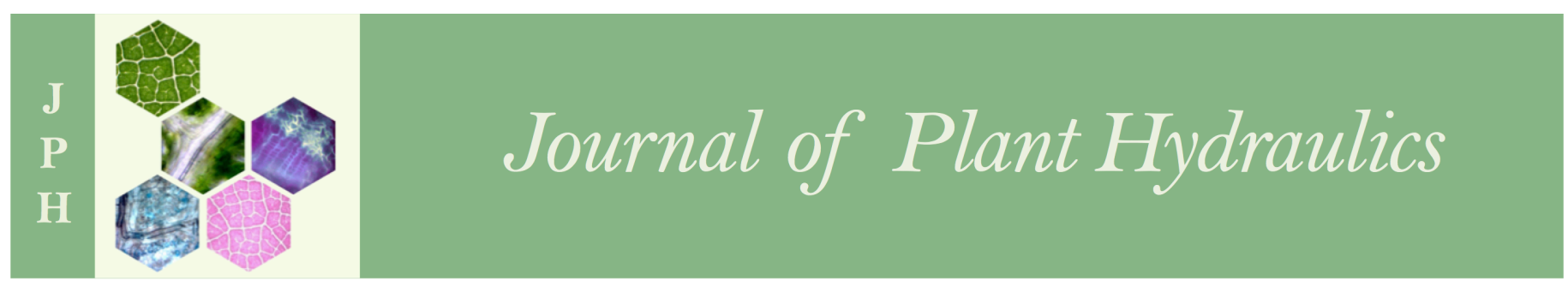

Journal of Plant Hydraulics 2: e-003

LETTER to JPH

\title{
Fine-scale mapping of sapwood anatomical properties reveals plasticity in hydraulics during water deficit
}

\author{
Patrick J. Mitchell ${ }^{1}$, Dale Worledge ${ }^{1}$ \\ ${ }^{1}$ CSIRO Land and Water; Hobart, Tasmania, Australia
}

Corresponding author: Patrick Mitchell, Patrick.Mitchell@csiro.au

Date of submission: October 22, 2015

Date of publication: November 10, 2015

\begin{abstract}
Growth responses to water deficit translate into discernible changes in the structure of woody tissues and provide an integrated record of historical water availability throughout the life of the individual. The highly dynamic nature of woody growth can impart adaptive changes in physiological performance through changes in xylem elements that regulate water transport. Here, we present a case study of how sapwood anatomical properties can be mapped using point dendrometers, in a diffuse porous, Eucalyptus spp. to reveal plasticity in hydraulic architecture under water deficit. Reductions in stem growth in response to water deficit coincided with marked changes sapwood vessel anatomy that could be matched to the commencement of large fluctuations in stem radius. These changes included: a reduction in hydraulically-weighted vessel diameter, increases in vessel density, sapwood lumen fraction and density and increase in wall strength. However, no changes in estimated stem conductivity were observed during the water deficit. This approach emphasises the responsiveness of species such as Eucalyptus to changes in water supply and provides an illustration of how we might detect short-term and rapid changes in stem hydraulic architecture in response to water availability and other environmental controls.
\end{abstract}

\section{Introduction}

The dynamic response of woody species to water availability includes several lasting changes in their structure and function. Growth responses to water deficit translate into discernible changes in the structure of woody tissues and provide an integrated record of historical water availability throughout the life of the individual. While inter-annual and seasonal variation in stem anatomy and other chemical properties may provide surrogates for reconstructing climatic water availability over decadal scales and longer (Allen et al. 2011), the finer scale patterns in woody growth reflect plasticity in physiological performance through changes in xylem elements that regulate water transport. These shorter-term changes (days to months) in xylem anatomy may facilitate whole-plant changes in hydraulic functioning that ensures homeostasis of water status and potentially enhanced resistance to severe hydraulic damage.

Mapping finer scale dynamics in wood properties has advanced significantly in the past two decades, with approaches capable of linking sub-daily patterns in radial growth (using point dendrometers) (De Swaef et al. 2015) to the wood properties of the corresponding tissues (SilviScan) (Evans 1994) at the time they were formed (Downes et al. 2009). While these mapping approaches have elucidated environmental drivers of wood properties relevant to timber and pulp production (Drew et al. 2009), the relevance of these changes in sapwood anatomy to plant hydraulic architecture has received less attention. A fine-scale temporal record of xylem formation can be related to other relevant ecophysiological attributes across the plant that reflects changes in hydraulic regulation such as gas exchange. Here, we present a case study of how sapwood anatomical properties can be mapped over the course of a short-term (12 weeks), chronic water deficit treatment, to illustrate the potential for this approach in understanding hydraulic plasticity in woody species. 


\section{Materials and Methods}

The data for sub-daily changes in stem radius and stem hydraulic properties where obtained from a chronic water deficit experiment detailed in Mitchell et al. (2014). Briefly, a chronic water deficit treatment was imposed on six, two-year old Eucalyptus globulus saplings (six well-watered saplings as controls) and maintained for $\sim 12$ weeks. The watering regime for the drought-treated saplings was designed to induce water deficit gradually and moderate water deficit intensities just above or below stomatal closure (Mitchell et al. 2014). Three individuals from each treatment were instrumented with point dendrometers, which measured stem radius (over bark) every 5 mins (see Mitchell et al. 2014 for details). Changes in stem radius were monitored for $\sim 3$ weeks prior to the imposition of the water deficit and continued throughout the experiment. Leaf water potential at pre-dawn and midday was measured approximately every two weeks as detailed in Mitchell et al. (2014).

Stem hydraulic properties were collected on all three individuals per treatment at the end of the experiment. Stem samples (radial slices $\sim 10 \mathrm{~mm}$ wide) were taken at $\sim 0.15 \mathrm{~m}$ above the soil surface from radial profiles across the entire stem that aligned with the placement of the dendrometer point and attachment rod (on instrumented trees). The sampling of the sapwood was done to enable scaling of changes in sapwood vessel anatomy to the high-resolution stem radius data (see Downes et al. (2009)). Transverse sections were made on stem samples (two per individual) using a freeze-microtome $(20-30 \mu \mathrm{m}$ thickness) that included the entire radial profile of the sapwood formed during the experiment. Intact stem sections were stained with toluidine blue, rinsed and mounted on slides with phenol glycerine for microscopy. Digital images of sapwood material were made using a compound light microscope and digital camera at $100 \times$ (Carl Zeiss Inc., NY) across these radial profiles and the sapwood hydraulic properties were computed using imaging software (Image J, 1.32J, USA Institutes of National Health).

To define differences in hydraulic properties during the experiment, each radial profile was partitioned into three radial segments (and corresponding time periods) of interest; pre-treatment (mid point at 1 day of water deficit), first half (mid point at 35 days or 5 weeks of water deficit) and second half of the treatment (at 69 or 10 weeks days of water deficit). Hydraulically weighted mean vessel diameter $\left(\sum d^{5} / \sum d^{4}\right)$ (Kolb and Sperry 1999), vessel density and lumen fraction was calculated on each radial segment ( $n>50$ conduits). Wall strength or level of reinforcement was estimated from the relationship between wall thickness $(t)$ and the average of the maximum and minimum diameters of each lumen $(b)$, using $\left(t / b^{2}\right)$ (Hacke et al. 2001). These calculations involved finding vessel pairs that were separated only by wall material. ( $n>5$ per segment) This has been shown to scale with resistance to cavitation among different species (Blackman et al. 2010; Hacke et al. 2001) and was used to infer potential changes in vulnerability to cavitation in the sapwood. Estimated total conductivity per stem cross-sectional area $\left(K_{\mathrm{s}}\right)$ was calculated following Zanne et al. (2010) using: $K_{\mathrm{s}} \alpha F^{1.5} S^{0.5}$, where $F$ is the lumen fraction and $S$ is the vessel size (cross-sectional area) multiplied by vessel density. Sapwood density was determined on samples directly below those used for sapwood anatomy measurements and each radial slice was carefully divided into sapwood formed during the experimental treatment and older sapwood. Differences in mean leaf water potential and sapwood hydraulic properties were tested using a two-way ANOVA using treatment and radial segment/time period as factors $(P<0.05)$. Differences in sapwood density between treatments were evaluated using a student's t-test $(P<0.05)$.

\section{Results}

The water deficit treatment induced clear differences in growth with stem radius being $40 \%$ lower in the water deficit treatment (Figure 1a and c). The sub-daily patterns of stem radius changes reflected large fluctuations in soil water availability after 2 weeks of the water deficit treatment, with periods of stem shrinkage, being followed by rapid expansion upon re-watering (Figure 1c). These rapid fluctuations in stem radius corresponded to significant reductions in leaf water status, with pre-dawn and midday leaf water potential declining during the middle and latter stages of the water deficit treatment (Figure 1e and f).

Reductions in stem growth coincided with marked changes sapwood vessel anatomy that could be matched to the commencement of large fluctuations in stem radius (Figure $1 \mathrm{~b}$ and d). Hydraulically-weighted vessel diameter declined under water deficit and was significantly lower during the last four weeks of the water deficit treatment (68 versus $88 \mu \mathrm{m}$ in water deficit and control respectively; Figure 2a). Lumen fraction and vessel density increased dramatically after five weeks of water deficit and continued to increase as the water deficit continued (Figure $2 b$ and c). Wall strength $\left(t / b^{2}\right)$ displayed a similar trend and was four times higher by the last four weeks of the water deficit treatment (Figure 2d). No changes in $K_{\mathrm{s}}$ were observed during the water deficit treatment (Figure 2e). The changes in sapwood vessel anatomy coincided with significant changes in sapwood density with the water deficit treatment inducing a decline in wood density of approximately $10 \%$ (mean of 0.49 versus $0.54 \mathrm{~cm}^{3} \mathrm{~g}^{-1}$ for water deficit and control trees respectively; data not shown). 

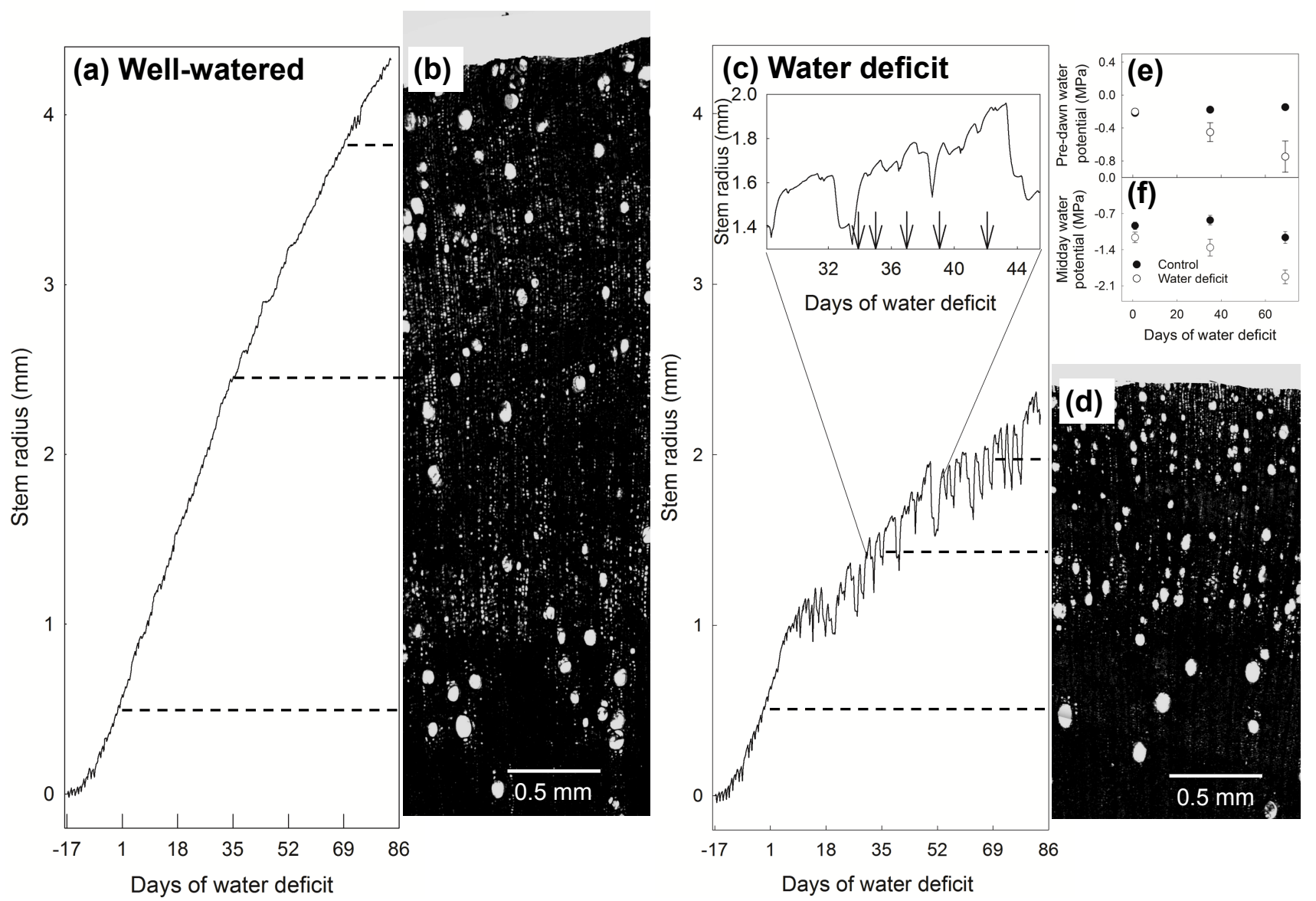

Figure 1: An example of the approach for mapping sapwood hydraulic properties using high-resolution stem radius measurements and sapwood radial profiles for trees exposed to well-watered (control) and water deficit conditions. Stem radius changes (at 15 min intervals) in (a) control (well-watered) and (c) water deficit treatments. The inset in (c) highlights the rapid response of stem radius to re-watering events (denoted by the arrows). The corresponding sapwood radial profile scaled to match the radius data for (b) control (well-watered) and (d) water deficit treatments. The dashed lines denote the mid-point of the three radial segments analysed for sapwood anatomy. Mean ( \pm 1 s.e.) (e) pre-dawn and (f) midday leaf water potential for the three time periods (corresponding to the dashed lines in (a) and (c)).

\section{Discussion}

This case study provides an illustration of how we can evaluate fine-scale plastic responses in stem hydraulic architecture to water deficit. This approach has the potential to identify the key triggers of functional changes in the xylem of woody species particularly in species such as Eucalyptus where their indeterminate growth and lack of distinguishable growth rings make understanding environmental controls of growth and hydraulic architecture very challenging. This information would also complement recent advances in measuring and imaging xylem properties such as X-ray microtomography (micro-CT) that can map variability in cavitation resistance within and between different regions of growth (Dalla-Salda et al. 2014).

Changes in sapwood anatomy in E. globulus saplings was evidenced by significant shifts in vessel dimensions and configuration, illustrating changes in xylem structure can occur within days of the plant experiencing changes in water status and a slowing or cessation of growth. The dependency of developing cells within the cambial zone on water potential and hormonal changes translates into a slowing of vessel expansion and wood formation during water deficit (Cosgrove 1986). As water deficit intensified in this study, expansive growth ceased intermittently and resumed upon re-watering (Figure 1c). A large proportion of the transient declines in stem radius was likely due to shrinkage of bark tissues (Figure 1c), however over multiple phases of shrinkage and enlargement, expansive growth and subsequent changes in xylem radius could be distinguished by a sustained radial increase despite these short-term fluctuations. The resultant impact of reduced expansive growth on sapwood anatomy in angiosperms tends to be smaller vessels, a denser configuration of vessels that generates higher sapwood density (Drew et al. 2009; Searson et al. 2004). However, these anatomical changes in response to water deficit did not translate into marked reductions $K_{\mathrm{s}}$ during water deficit treatment (Figure 2e) indicating the reductions in vessel diameter were compensated for by increases in vessel density and sapwood lumen fraction. This suggests that some maintenance of sapwood-specific conductivity is maintained across xylem tissue despite significant alterations in the configuration and size distribution of the vessel elements. 


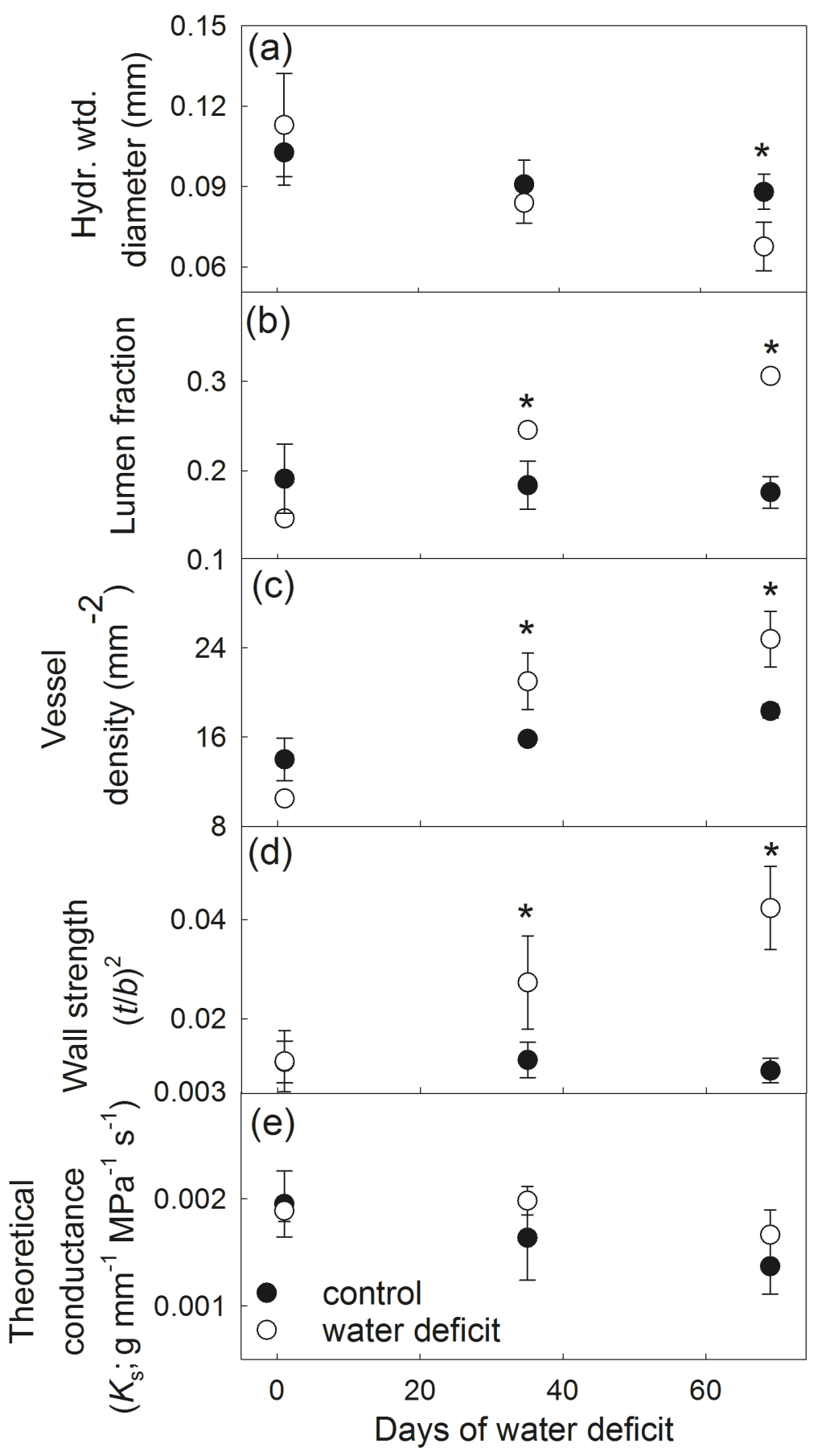

Figure 2: Response of sapwood hydraulic properties to chronic water deficit averaged over three different radial segments (centered on day 1 , day 35 and day 69 of water deficit treatment). (a) hydraulically weighted vessel diameter, (b) lumen fraction, (c) vessel density, (d) wall strength $\left(t / b^{2}\right)$ and (e) theoretical conductance or estimated total conductivity per stem cross-sectional area $\left(K_{\mathrm{s}}\right)$ (data are means \pm 1 s.e). Asterisks above symbols denote significant difference between control and water deficit treatments based on pair-wise comparisons $(P<0.05)$.

In this study we also found that wall strength tends to increase in concert with these other anatomical changes, suggesting that an outcome of the observed plasticity in sapwood anatomy may include increases in cavitation resistance. Changes in stem cavitation resistance under prolonged water deficit conditions (such as those observed in this study) are not a common functional response in many species (e.g. Martin -StPaul et al. 2013; Delaporte et al. 2015), but under certain water deficit conditions that permit continued albeit diminished expansive growth in sapwood tissues, this may eventually affect whole stem cavitation resistance. Further research is needed to understand the capacity for temporal changes in cavitation resistance in species experiencing long-term reductions in water availability (Anderegg 2015).

\section{Acknowledgements}

We thank Isaac Meos for his assistance with the pot experiments and acknowledge the support of Stephen Burgess for assistance with the design of the point dendrometer system. 


\section{References}

Allen KJ, Ogden J, Buckley BM, Cook ER, Baker PJ. 2011. The potential to reconstruct broadscale climate indices associated with southeast Australian droughts from Athrotaxis species, Tasmania. Climate Dynamics 37: 17991821.

Anderegg WRL. 2015. Spatial and temporal variation in plant hydraulic traits and their relevance for climate change impacts on vegetation. New Phytologist 205: 1008-1014.

Blackman CJ, Brodribb TJ, Jordan GJ. 2010. Leaf hydraulic vulnerability is related to conduit dimensions and drought resistance across a diverse range of woody angiosperms. New Phytologist 188: 1113-1123.

Cosgrove DJ. 1986. Biophysical control of plant cell growth. Annual Review of Plant Physiology 37: 377-405.

De Swaef T, De Schepper V, Vandegehuchte MW, Steppe K. 2015. Stem diameter variations as a versatile research tool in ecophysiology. Tree Physiology 35: 1047-1061.

Delaporte A, Bazot S, Damesin C. 2015. Reduced stem growth, but no reserve depletion or hydraulic impairment in beech suffering from long-term decline. Trees (in press) DOI 10.1007/s00468-015-1299-8

Downes G, Drew D, Battaglia M, Schulze D. 2009. Measuring and modelling stem growth and wood formation: an overview. Dendrochronologia 27: 147-157.

Drew DM, Downes GM, O'Grady AP, Read J, Worledge D. 2009. High resolution temporal variation in wood properties in irrigated and non-irrigated Eucalyptus globulus. Annals of Forest Science 66: 406.

Evans R. 1994. Rapid measurement of the transverse dimensions of tracheids in radial wood sections from Pinus radiata. Holzforschung 48: 168-172.

Dalla-Salda G, Fernández ME, Sergent A-S, Rozenberg P, Badel E, Martinez-Meier A. 2014. Dynamics of cavitation in a Douglas-fir tree-ring: transition-wood, the lord of the ring? Journal of Plant Hydraulics 1: e-0005.

Hacke UG, Sperry JS, Pockman WT, Davis SD, McCulloh KA. 2001. Trends in wood density and structure are linked to prevention of xylem implosion by negative pressure. Oecologia 126: 457-461.

Kolb KJ, Sperry JS. 1999. Differences in drought adaptation between subspecies of Sagebrush (Artemisia Tridentata). Ecology 80: 2373-2373.

Martin-StPaul NK, Limousin J-M, Vogt-Schilb H, Rodríguez-Calcerrada J, Rambal S, Longepierre D, Misson L. 2013. The temporal response to drought in a Mediterranean evergreen tree: comparing a regional precipitation gradient and a throughfall exclusion experiment. Global Change Biology 19: 2413-2426.

Mitchell PJ, O'Grady AP, Tissue DT, Worledge D, Pinkard EA. 2014. Co-ordination of growth, gas exchange and hydraulics define the carbon safety margin in tree species with contrasting drought strategies. Tree Physiology 34: $443-458$.

Searson MJ, Thomas DS, Montagu KD, Conroy JP. 2004. Wood density and anatomy of water-limited eucalypts. Tree Physiology 24: 1295-1302.

Zanne AE, Westoby M, Falster DS, Ackerly DD, Loarie SR, Arnold SEJ, Coomes Da. 2010. Angiosperm wood structure: Global patterns in vessel anatomy and their relation to wood density and potential conductivity. American Journal of Botany 97: 207-215. 